\title{
PERSEPSI PEMUSTAKA DALAM MEMANFAATKAN ONLINE PUBLIC ACCCES CATALOG BERBASIS SLIMS PADA PERPUSTAKAAN SEKOLAH TINGGI PERIKANAN JURUSAN PENYULUH PERIKANAN BOGOR Library Users Perception of The Use of Online Public Acces Catalogue
Based on Slims at The Library of The School of Fishery Department
of Fishery Extention Bogor
}

\author{
Erny Puspa
}

Pusat Penelitian dan Pengembangan Perikanan Budidaya

Diterima tanggal: 12 Oktober 2015 Diterima setelah perbaikan: 10 Nopember 2015 Disetujui terbit: 27 Nopember 2015

\begin{abstract}
ABSTRAK
Pemanfaatan online Public Acess Catalogue (OPAC) untuk mempermudah akses informasi kepada pemustaka di perpustakaan STP Jurluhkan Bogor, hingga kini belum optimal. Kenyataan ini ditunjukkan dengan masih banyaknya pemustaka yang mencari buku langsung ke rak atau bertanya kepada petugas. Tujuan penelitian untuk mengetahui persepsi pemustaka terhadap pemanfaatan OPAC. Penelitian dilakukan menggunakan metode deskriptif kuantitatif. Teknik pengumpulan data menggunakan observasi, kuesioner, dan studi pustaka. Sebanyak 75 pemustaka telah dipilih sebagai responden melalui rumus Taro Yamane. Hasil penelitian menunjukkan persepsi pemustaka dalam kategori ideal khususnya: pemahaman, kualitas tampilan, kemudahan penggunaan, ketepatan data OPAC berbasis SLiMS, sumberdaya manusia dan data koleksi mutakhir. Adapun persepsi pemustaka dalam kategori tidak ideal yaitu data koleksi OPAC belum dapat memenuhi kebutuhan pemustakanya karena belum semua koleksi dientri ke dalam OPAC mengakibatkan ketidaksesuaian antara koleksi yang tersimpan di rak dengan data yang ditampilkan di OPAC. Selain itu, penempatan koleksi yang salah menyebabkan pemustaka kesulitan dalam penelusuran sehingga mereka lebih banyak bertanya kepada petugas daripada menelusur melalui OPAC. Upaya yang dilakukan adalah menyegerakan pengentrian data ke dalam OPAC dan meningkatkan shelving di rak, memberi bimbingan kepada pemustaka baik secara lisan maupun praktik, dan membuat petunjuk penggunaan OPAC. Demikian pulapersepsi pemustaka terhadap sarana dan prasarana dikategorikan tidak ideal karena satu komputer OPAC tidak cukup sebagai sarana penelusuran maka perlu diupayakan penambahan komputer OPAC guna mengatasi antrian penggunaannya.
\end{abstract}

Kata Kunci: persepsi, pemustaka, OPAC, SLiMS, perpustakaan, STP Jurluhkan Bogor

\begin{abstract}
The use of Online Public Access Catalogue (OPAC) as an easy access to information at the Bogor School of Fishery, Department of Fishery Extension, has not been optimized. Most of library users would go through the bookshelves or simply ask the officers for books that they look for. This study aims to understand the users perception of the OPAC. The study was conducted using descriptive- quantitative method. The data collection technique was done by observation, questionnaire, and literature reviews. There are as many as 75 users chosen as respondents by using Taro Yamane formula. The research outcome shows ideal perception of users that include understanding, appearance quality, user-friendliness; OPAC data precision based on SLiMS, human resources and sophisticated data collection. The users perception that is considered unsatisfactory includes OPAC data collection that hasn't met the users expectation as not all collection are uploaded into the OPAC system, leading to the inconsistency of collected items in the bookshelves to the data shown in the OPAC. In addition, disorganized book collection causes difficulties among users when searching for the items they need that they prefer to ask the librarian rather than looking for the book themselves through OPAC. To tackle with the issues, efforts were made such as data collection updating, improving the organization of books on bookshelves, oral and practical training for users and making OPAC user guideline available. Insufficient facility is also considered as unsatisfactory as one computer only is not enough and therefore addition of facility is needed to help ease long queue.
\end{abstract}

Keywords: perception; library users; OPAC; SLiMS; library; STP Jurluhkan Bogor

Korespondensi Penulis:

Jl. Ragunan No. 20 Pasar Minggu Jakarta Selatann. 12540

Email: erny.puslitbangkan@gmail.com 


\section{PENDAHULUAN}

Salah satu tugas perpustakaan adalah memberikan layanan informasi kepada pemustaka melalui layanan penelusuran. Penelusuran adalah kegiatan menelusur kembali seluruh atau sebagian informasi yang pernah ditulis atau diterbitkan melalui sarana temu kembali (Purwono, 2008: 2). Sedangkan Temu kembali informasi merupakan istilah generik yang mengacu pada temu balik dokumen atau sumber daya informasi yang dimiliki oleh unit informasi (vendor) atau perpustakan baik yang berada di dalam maupun di luar gedung perpustakaan (Hasiguan, 2008: 13). Oleh karena itu katalog online atau OPAC (Online Public Access Catalogue) berperan penting dalam penemuan kembali sebuah informasi.

Perpustakaan Sekolah Tinggi Perikanan (STP) Jurusan Penyuluhan Perikanan (Jurluhkan) Bogor merupakan perpustakaan di bawah kementerian Kelautan dan Perikanan yang didirikan untuk menunjang pelaksanaan program Tri Dharma Perguruan Tinggi: pendidikan dan pengajaran, penelitian dan pengabdian pada masyarakat khususnya bidang kelautan dan perikanan (http://www. perpustakaan-stpbogor.kkp.go.id). Oleh karena itu perpustakaan dituntut dapat memberikan pelayanan yang baik, cepat dan tepat dengan menggunakan sarana OPAC berbasis SLiMS. Menurut Hermanto (dalam Martina Monisa, 2007) OPAC memiliki keuntungan, yaitu penelusuran informasi koleksi dapat dilakukan secara cepat dan tepat. sehingga dengan menggunakan OPAC dapat menghemat waktu dan tenaga pemustaka. Di samping itu pemustaka dapat mengetahui keberadaan koleksi dan status koleksi apakah sedang dipinjam atau tidak.

Berdasarkan pengamatan penulis di perpustakaan STP, pemanfaatan OPAC belum optimal karena masih banyak pemustaka yang langsung menuju ke rak atau bertanya kepada petugas dalam melakukan penelusuran informasi. Atas dasar permasalahan tersebut maka penulis melakukan penelitian tentang persepsi pemustaka terhadap pemanfaatan OPAC ini dengan maksud agar efektivitas fungsi OPAC dapat ditingkatkan di masa depan. Tujuan penelitian ini adalah untuk mengetahui pemahaman dan kualitas pemustaka terhadap OPAC berbasis SLiMS serta persepsi pemustaka terhadap koleksi yang ada di OPAC, sumberdaya manusia (petugas) layanan perpustakaan, dan sarana serta prasarana OPAC.

\section{RUMUSAN MASALAH}

Berdasarkan latar belakang tersebut di atas, maka yang menjadi rumusan masalah adalah:

1. Bagaimana pemahaman dan kualitas terhadap OPAC berbasis SLiMS

2. Bagaimana persepsi pemustaka terhadap koleksi pada OPAC

3. Bagaimana persepsi pemustaka terhadap sumberdaya manusia

4. Bagaimana persepsi pemustaka terhadap sarana dan prasarana OPAC

\section{METODE PENELITIAN}

Penelitian ini menggunakan metode deskriptif kuantitatif. Data diperoleh melalui hasil observasi, kuesioner, dan studi pustaka. Responden yang terlibat dalam pengisian kuesioner adalah pemustaka yang memanfaatkan OPAC di STP Jurluhkan Bogor. Sampel responden diambil dengan menggunakan teknik Sampling Aksidental. Penetapan jumlah sampel penelitian dilakukan dengan menggunakan rumus Taro Yamane. Hasil perhitungan dari 300 pemustaka, diperoleh sampel sebanyak 75 orang. Rumus Taro Yamane yang dimaksud adalah sebagai berikut:

$$
n=\frac{N}{1+N^{*}(e)^{2}}
$$

$\mathrm{n}=$ Jumlah pemustaka

$\mathrm{N}=$ Total pemustaka

$\mathrm{e}=$ Kesalahan sampel yang dapat diterima

(95\% level yang dapat dipercaya, $p=0,5$ adalah asumsi)

Data kuantitatif yang diperoleh dalam penelitian ini selanjutnya ditabulasi atau disajikan dalam bentuk tabel dan diberi interpretasi, kemudian dilakukan dianalisis secara kualitatif. Hasil jawaban yang terkumpul selanjutnya dihitung sesuai dengan yang dilakukan oleh 
Sudijono (1991: 40) sebagai berikut:

$$
\mathrm{P}=\frac{\mathrm{F}}{\mathrm{N}} \mathrm{x}
$$

$\mathrm{P}=$ Persentase

$\mathrm{F}=$ Frekuensi jawaban responden

$\mathrm{N}$ = Sampel yang diolah

Untuk mengetahui kelemahan dan hambatannya, data jawaban responden pada setiap item pertanyaan diklasifikasikan menjadi 2 kategori, yaitu Kategori ideal dan Kategori tidak ideal. Dikatakan ideal, jika responden memilih jawabannya dengan a atau b. Dan kategori tidak ideal apabila responden memilih jawaban c atau d dari alternative jawaban yang tersedia. Untuk mengukur kondisi perpustakaan diambil batas jawaban ideal sekurang-kurangnya $70 \%$, artinya apabila jawaban ideal dari responden pada setiap item pertanyaan mencapai $70 \%$, kondisi perpustakaan tidak mendesak untuk ditingkatkan.

\section{HASIL DAN PEMBAHASAN}

\section{Persepsi Pemustaka}

Hasil pengisian kuesioner dari responden diperoeh nilai ideal dan tidak ideal sebagaimana yang terlihat dalam Tabel 1.

Tabel 1. Akumulasi Tabulasi Persepsi Pemustaka Terhadap Pemanfaatan OPAC

\begin{tabular}{|c|c|c|c|}
\hline \multirow[b]{2}{*}{ Pertanyaan } & \multicolumn{3}{|c|}{ Pilihan Jawaban } \\
\hline & Ideal & $\begin{array}{l}\text { Tidak } \\
\text { ideal }\end{array}$ & $\begin{array}{c}\text { Upaya } \\
\text { Peningkatan }\end{array}$ \\
\hline
\end{tabular}

Pemahaman Responden terhadap Online Public Access Catalogue (OPAC)

1. Anda mengetahui cara menggunakan Online Public Acces Catalog $\quad 72 \quad 28$ (OPAC) berbasis SLiMS di Perpustakaan STP Jurluhkan Bogor

2. OPAC berbasis SLiMS pada Sekolah Tinggi Perikanan Jurluhkan Bogor mudah digunakan/dioperasikan

3. Anda tidak pernah mengalami kesulitan dalam menggunakan OPAC di 76 Perpustakaan STP Jurluhkan Bogor

\section{Kualitas Online Public Access Catalogue (OPAC) berbasis SLiMS}

4. Menurut Anda tampilan aplikasi OPAC berbasis SLiMS di monitor sangat menarik

5. Menurut Anda pemakaian font (jenis huruf) pada OPAC berbasis SLiMS dapat terlihat jelas

6. Menurut Anda proses pencarian informasi dengan menggunakan OPACberbasis SLiMS mudah dipahami karena tampilan deskripsinya familiar dan didisain sesuai dengan kebutuhan anda

7. Dengan menggunakan OPAC berbasis SLiMS, Anda lebih mudah menemukan koleksi yang anda butuhkan

8. Apabila koleksi tidak diketemukan, OPAC berbasis SLiMS dapat memberikan alrenatif koleksi yang lain dengan subjek yang sama

9. Dengan mengetikkan nama pengarang, OPAC berbasis SLiMS dapat menampilkan seluruh karya yang dikarang oleh pengarang tersebut.

10. Dengan mengetikkan subjek (kata kunci) pada OPAC berbasi SLiMS dapat memberikan informasi /cantuman daftar seluruh koleksi yang memiliki subjek yang sama

Koleksi dalam Online Public Access Catalogue (OPAC) berbasis SLiMS

11. Koleksi yang terdapat pada OPAC berbasis SLiMS di Perpustakaan STP Jurluhkan mutakhir sesuai dengan perkembangan informasi

12. Data koleksi yang terdapat pada OPAC sesuai dengan koleksi yang tersedia di rak koleksi

13. Koleksi bahan pustaka yang terdapat dalam OPAC ber basis SLiMS sudah memenuhi kebutuhan Anda sebagai pemustaka 
Lanjutan Tavel 1/ Continue Table 1

\begin{tabular}{|c|c|c|c|}
\hline \multirow[b]{2}{*}{ Pertanyaan } & \multicolumn{3}{|c|}{ Pilihan Jawaban } \\
\hline & Ideal & $\begin{array}{l}\text { Tidak } \\
\text { ideal }\end{array}$ & $\begin{array}{c}\text { Upaya } \\
\text { Peningkatan }\end{array}$ \\
\hline $\begin{array}{l}\text { 14. Anda senantiasa menelusur bahan pustaka melalui OPAC dari pada } \\
\text { langsung menujun rak koleksi }\end{array}$ & 38.7 & 61.3 & \\
\hline \multicolumn{4}{|l|}{ Faktor Sumber Daya Manusia } \\
\hline $\begin{array}{l}\text { 15. Petugas perpustakaan STP Jurkuhkan sudah menguasai penggunaan } \\
\text { OPAC berbasis SLiMS }\end{array}$ & 70 & 30 & - \\
\hline $\begin{array}{l}\text { 16. Petugas perpustakaan STP Jurluhkan sangat membantu apabila Anda } \\
\text { menemukan kesulitan dalam melakukan penelusuran melalui OPAC } \\
\text { Perpustakaan STP }\end{array}$ & 93.4 & 6.6 & - \\
\hline $\begin{array}{l}\text { 17. Dalam mencari informasi/bahan pustaka Anda lebih sering bertanya } \\
\text { kepetugas daripada menggunakan OPAC }\end{array}$ & 78.6 & 21.4 & \\
\hline $\begin{array}{l}\text { 18. Jumlah petugas Perpustakaan STP sudah cukup dalam membantu } \\
\text { pemustaka dalam pengoperasian OPAC berbasis SLiMS }\end{array}$ & 78 & 22 & \\
\hline \multicolumn{4}{|l|}{ Faktor Sarana Dan Prasarana } \\
\hline $\begin{array}{l}\text { 19. Menurut Anda Jumlah komputer fasilitas OPAC sudah memadai dengan } \\
\text { kebutuhan pengguna }\end{array}$ & 28 & 72 & \\
\hline 20. Kondisi ruangan penggunaan OPAC tenang dan nyaman & 72 & 28 & - \\
\hline
\end{tabular}

Berdasarkan Tabel 1 diatas maka analisis kelemahan ("tidak ideal") yang harus diatasi adalah sebagai berikut:

1. Ketidak sesuaian antara data koleksi di OPAC dan di rak.

Ketidakcocokan antara data koleksi di OPAC dengan data koleksi di rak diketahui ketika data koleksi tidak ditemukan di OPAC, namun dapat ditemukan dalam rak koleksi. Berdasarkan hasil pengamatan, penyebab ketidaksesuaian data koleksi di OPAC dengan data koleksi di rak disebabkan oleh:

a. Entri data ke dalam OPAC baru berjumlah setengah (2.900 judul) dari total koleksi yang ada di perpustakaan (5.500 judul).

b. Kesalahan penempatan koleksi bahan pustaka di rak oleh pemustaka. Hal ini disebabkan pemustaka mencari langsung ke rak kemudian mengembalikan lagi tanpa memperhatikan tatanan label yang sudah ditentukan sehingga terjadi ketidakcocokkan antara data di OPAC dengan koleksi bahan pustaka di rak. Terjadinya kesalahan penempatan koleksi ini karena perpustakaan menggunakan sistim layanan terbuka, dimana pemustaka dapat langsung memilih sendiri bahan pustaka di rak sehingga memungkinkan kesalahan penempatan kembali koleksi oleh pemustaka.

2. Koleksi bahan pustaka yang terdapat dalam OPAC berbasis SLiMS belum dapat memenuhi kebutuhan pemustaka karena belum semua data koleksi di terentri ke dalam OPAC.

3. OPAC belum memenuhi kebutuhan pemustakanya dalam proses penelusuran, sebagai akibat metadata yang kurang lengkap sehingga pemustaka lebih senang menuju ke rak koleksi dan bertanya langsung kepada petugas. Penyebab kategori tidak ideal terkait dengan OPAC adalah karena pemustaka:

a. kesulitan dalam mencari bahan pustaka yang dibutuhkan, sebagai akibat salah letak dan salah kode dalam penempatan koleksi ke lokasi dan data bibliografi koleksi yang belum seluruhnya terentri dalam sistem.

b. masih banyak yang belum mengetahui cara menggunakan OPAC.

4. Kurangnya fasilitas sarana dan prasarana (komputer) OPAC

Sarana komputer untuk penelusuran OPAC yang tersedia di perpustakaan hanya 1unit, sedangkan 2 unit lainnya untuk 
mahasiswa yang mengerjakan tugas, dan 2 unit berikutnya untuk kegiatan pengelolaan perpustakaan. Sarana komputer sebagai alat penelusuran OPAC yang hanya tersedia 1 unit dinyatakan sebagai layanan yang tidak ideal karena proses penelusuran menjadi lambat akibat harus antri dalam menggunakan OPAC.

\section{Upaya Mengatasi" Tidak idealnya Layanan" dan Persepsi Pemustaka}

Upaya untuk mengatasi ketidak sesuaian antara data koleksi di OPAC dan di rak:

1. Mempercepat entri data ke dalam OPAC dengan berbasis SLiMS

Dengan menggunakan OPAC berbasis SLiMS dapat mempermudah dan mempercepat petugas dalam pengentrian data dan melalui OPAC juga memudahkan pemustaka dalam melakukan penelusuran informasi, sebagaimana yang dinyatakan oleh Abdoulaye dalam Devendra (2012 :37) bahwa "The OPAC is an important tool in helping users for the localisation of library resources effectively". Selanjutnya dijelaskan bahwa OPAC menyediakan katalog online untuk membantu pengguna dalam mengidentifikasi dan menemukan bahan pustaka dengan mudah. Tujuan disedikannya OPAC sebagaimana yang diutarakan oleh Kusmayadi (2006: 53) :

\begin{abstract}
Pengguna dapat mengakses secara langsung ke dalam pangkalan data yang dimiliki perpustakaan, mengurangi beban biaya dan waktu yang diperlukan dan yang harus dikeluarkan oleh pengguna dalam mencari informasi, mengurangi beban pekerjaan dalam pengelolaan pangkalan data sehingga dapat meningkatkan efisiensi tenaga kerja, dan mempercepat pencarian informasi. Selain itu dengan adanya OPAC, perpustakaan dapat melayani kebutuhan informasi masyarakat dalam jangkauan luas.
\end{abstract}

Untuk mempercepat pengentrian data dapat dilakukan melalui penambahan jam kerja (lembur) atau penambahan tenaga pengentri dengan mempertimbangkan alokasi anggaran sebagai honor mereka.

2. Penempatan kembali ke rak secara benar (shelving)
Sistim pelayanan terbuka mengharuskan pemustaka mencari sendiri bahan pustaka ke rak. Akibat dari dari sistem ini banyak terjadi kesalahan dalam pengembalian dan penempatan bahan pustaka yang tidak sesuai antara kode bahan pustaka di rak dengan di OPAC. Oleh karena itu perlu peningkatan kinerja petugas perpustakaan dalam melakukan shelving. Kegiatan shelving seharusnya dilakukan secara rutin yaitu setiap kali perpustakan akan buka dan tutup.

\section{Pedoman pemakaian koleksi}

Perpustakaan perlu membuat pedoman pemakaian koleksi bagi pemustaka. Peraturan perpustakaan yang sudah ada dimaksudkan untuk memelihara ketertiban di perpustakaan dan hendaknya dituangkan secara tertulis dalam bentuk surat keputusan oleh pimpinan sekolah. Peraturan tertulis biasanya dikomunikasikan dalam bentuk rambu-rambu, brosur, poster, dan sebagainya (Depdikbud 2004: 88). Walaupun demikian pelayanan sistim terbuka pada perpustakaan STP Jurluhkan Bogor tetap akan dipertahankan sehingga pemustaka lebih leluasa memilih sendiri koleksi di rak sesuai dengan yang dibutuhkannya. Namun demikian, untuk menghindari ketidaksesuaian koleksi antara yang ada di rak dengan data di OPAC maka perlu dibuat pedoman khusus pemakaian koleksi bagi pemustaka. Hal ini dimaksudkan agar pemustaka menyadari pentingnya temu kembali koleksi dalam proses penelusuran selanjutnya.

4. Penambahan data dan bimbingan kepada pemustaka

Upaya untuk mengatasi pemustaka yang banyak bertanya pada petugas daripada menelusur informasi melalui OPAC, antara lain melalui:

a. Pengentrian data koleksi ke dalam OPAC.

b. Pelaksanaan shelving secara teratur.

c. Pembinaan pada pemustaka yang belum dapat menggunakan OPAC

Petugas perpustakaan dapat membimbing secara langsung melalui lisan dan praktek kepada pemustaka tentang bagaimana cara menelusur informasi dalam OPAC berbasis SLiMS. Perpustakaan perlu menyediakan petunjuk (secara tercetak) tentang cara menggunakan OPAC yang diletakkan di dekat komputer 
sebagai pedoman penelusuran, sebagaimana yang ditegaskan oleh Departemen Pendidikan dan Kebudayaan, Direktorat Jenderal Pendidikan Tinggi (1976: 37) menyatakan :

\section{Sarana perpustakaan perguruan} tinggi belum dianggap sempurna sampai perpustakaan itu memiliki staf baik laki-laki maupun perempuan yang bertugas, tidak hanya untuk memelihara dan mengkatalog buku tetapi memberikan bimbingan/ pendidikan tentang bagaimana cara menggunakan perpustakaan tersebut secara efektif.

\section{Menambah fasilitas komputer OPAC}

OPAC sangat membantu pemustaka untuk mencari informasi secara cepat dan tepat, Penelusuran akan terasa nyaman dan cepat jika jumlah unit komputer di bagian layanan digital sudah mencukupi. 1 unit komputer OPAC yang tersedia saat ini belum memadai jika dibandingkan dengan jumlah pemustaka di perpustakaan, rata-rata 50 orang per hari. Oleh sebab itu perpustakaan perlu menambah unit komputernya agar bisa memenuhi kebutuhan pemustaka.

Dalam upaya penambahan unit komputer di perpustakaan, perlu diperhatikan alokasi anggaran untuk sarana pengadaan komputer, sebagai pertimbangan agar penggantian dan pengadaan komputer dapat terealisasi dengan lancar sebaiknya pengadaan berpedoman pada buku: "Perpustakaan Perguruan Tinggi: Buku Pedoman" (Depdiknas, 2004: 20). disebutkan bahwa :

Perpustakaan memanfaatkan komputer sesuai dengan: 1) jumlah mutu layanan, 2) tuntutan untuk menggunakan koleksi secara bersama, 3) kebutuhan untuk lebih mengefektifkan tenaga, 4) kebutuhan akan efisiensi waktu, 5) ragam informasi yang dikelola, dan 6) kebutuhan kecepatan layanan.

\section{PENUTUP}

\section{Kesimpulan}

Berdasarkan hasil pembahasan diatas , dapat disimpulkan bahwa :
1. Persepsi permustaka terhadap pemahaman OPAC berbasis SLiMS ada dalam kategori ideal, dan persepsi kualitas OPAC terkait tampilan, kemudahan, dan ketepatan data dalam proses penelusuran informasi ada dalam kategori ideal.

2. Persepsi pemustaka terhadap pemenuhan kebutuhan koleksi ada dalam kategori tidak ideal. Adanya kendala dimana data koleksi di OPAC tidak sesuai dengan data koleksi di rak.

3. Persepsi pemustaka terhadap sumberdaya manusia ada dalam kategori ideal karena selalu memberi bantuan kepada pemustaka. Namun demikian tidak semua sumberdaya manusia di perpustakaan STP Jurluhkan memahami tentang OPAC berbasis SLiMS.

4. Persepsi pemustaka terhadap sarana dan prasarana ada dalam kategori tidak ideal akibat kurangnya fasilitas komputer untuk OPAC.

\section{Saran}

1. Perpustakaan perlu membuat petunjuk tentang "Tata Cara Penggunaan OPAC" yang diletakkan dekat OPAC dan membimbing pemustaka tentang cara menggunakan OPAC secara baik dan benar (secara lisan maupun praktek).

2. Perpustakaan perlu meningkatkan entri data koleksi kedalam OPAC dan melakukan shelving bahan pustaka secara rutin

3. Perpustakaan perlu meningkatkan kemampuan iptek sumberdaya manusianya agar lebih memahami tentang OPAC berbasis SLiMS (melalui pelatihan, workshop, studi banding, dll).

4. Perpustakaan harus menambah komputer OPAC sehingga pemustaka tidak perlu antri dalam melakukan penelusuran informasi.

\section{DAFTAR PUSTAKA}

Departemen Pendidikan Nasional RI. Direktorat Jenderal Pendidikan Tinggi. 2004. Pedoman perpustakaan perguruan tinggi. Jakarta.

Devendra \& Nikam, K. 2012. OPAC and user perception in law University Libraries in the Karnataka. Information Dissemination and Technology, 2 (4): 301-306. 
Hasugian, J. 2008. Penelusuran online dan ketersediaan sumberdaya informasi elektronik. Jurnal Studi Perpustakaan dan Informasi, 4 (1): 13.

Kementerian Kelautan dan Perikanan. 2014. Perpustakaan STP Jurluhkan Bogor. Diakses:05/12/2014.http://www. perpustakaan-://www. perpustakaanstpbogor.kkp.go.id/index.php?p=libinfo

Kusmayadi, Eka dan Andriaty. 2006. Kajian Online Public Access Catalogue (OPAC) dalam pelayanan Perpustakaan dan Penyebaran Teknologi Pertanian, Bogor. Jurnal Perpustakaan Pertanian, 15 (20): 51-58.

Monisa, M. 2013. Persepsi kemudahan dan kegunaan OPAC perpustakaan UNAIR. Diakses: 06/12/2014. http://journal.unair. ac.id/filerPDF/ Jurnal\% 20Martina.pdf.

Purwono, 2008. Strategi penelusuran informasi melalui internet. Diakses: 25/11/2014 http://eprints.rclis.org/12193/1/Strategi_ Penelusuran_melalui_Internet. 